\title{
Using CAI to teach library skills
}

\author{
By John E. Cooper
}

\section{Use the computer to orient large numbers of students efficiently}

$\mathbf{M}$ any academic libraries are involved in programs designed to help students develop library skills. These programs range from brief tours of the library for entering freshmen to in-depth seminars for graduate students on such topics as online searching or the development of bibliographic databases.

At large universities a common problem has been finding an effective way of handling such instruction for beginning students. Orientation tours of the library, used successfully with small classes, become unwieldy when they involve hundreds of students. The one-hour bibliographic instruction session, another frequently used format, may be perceived by students as irrelevant to their specific information needs. In either format students are too often passive recipients of instruction, retaining little of what is presented in the orientation.

One solution is the use of Computer-Assisted Instruction (CAI), which is particularly suitable for large, ongoing orientation programs. Because it also requires student involvement in the learning process, it can be an effective instructional aid in teaching basic library skills.

\section{UCR'S past experience}

For each of the past 13 years the Bio-Agricultural Library at the University of California, Riverside (UCR), has given library orientations to beginning biology students. The library's reference staff undertook this program at the request of the Biology Department, which wanted its students to learn how to locate scientific information in a library early in their academic careers. The course selected for the orientation was the introductory biology course, Biology 5A. The library was asked specifically to include an introduction to the basic life sciences index, Biological Abstracts, in the program.

Several instructional methods were tried including tours, in-library exercises, and a selfpaced workbook. In recent years the orientation evolved into a three-phase program:

1) An overview of ways to locate scientific information in our library, presented as a 40 minute lecture to a class of approximately 600 students during the second week of the quarter.

2) A library exercise in which the students used the online catalog, the microfiche list of UCR Serials, and Biological Abstracts. Each laboratory section came to the library to work on the exercise for one hour during one of the regularly scheduled lab periods.

3) A follow-up assignment requiring the students to locate scientific papers in the library for use as background material in two lab reports.

\section{Problems}

During the time the library has been involved in the orientation, Biology $5 \mathrm{~A}$ has grown from 250 students in 1979 to about 600 students at present and from being offered in a single quarter to now being offered in two quarters each academic year. We expect additional growth in the future as the UCR campus grows. Along with a greater number of students, we have noted a significant increase in the amount of library staff time required to give the orientation. In 1989 the orientation required approximately 486 hours of reference staff time, far too much to devote to a single course twice a year. 
Other problems we encountered were probably typical for this type of library orientation. We found:

1) The students seemed to retain very little useful information from the 40-minute lecture.

2) The program made intensive use of our reference staff. Acquainting each of 25 students in 24 separate lab sections with Biological $A b$ stracts and the online catalog required almost individual attention from these librarians.

3) There was severe overcrowding in the reference area where we shelve Biological $A b$ stracts. This area is so small that only 12 students can work effectively at one time, but during the 1989 sessions there were sometimes as many as 25 students attempting to use the same set of indexes. This slowed the students' progress and frustrated their attempts to learn.

4) The use of a single set of indexes by 600 students in a learning experience damaged an expensive library resource.

5) In the follow-up assignment students again required intensive help from the library staff, showing that they remembered little from the previous library exercise.

\section{Computer-assisted instruction}

We decided to turn to CAI as a way of solving some of these problems. Because the staff-intensive parts of the program involved training the students in the use of the online catalog and Biological Abstracts, these were the areas that were selected for computerization. For the convenience of the students, we chose a conventional CAI system that could be run on one of the IBM-PC or compatible microcomputer networks that are available on the campus.

After determining the objectives and outlining each proposed CAI program, we asked for comments from librarians who had been involved in past orientations. This input resulted in a shorter, more sharply focused program for the online catalog system and a decision to change the overall emphasis of the Biological Abstracts program to include a second index to biological literature.

Individual screens were then written and given to a professional programmer who created the final programs using PMI (Polytron) Repertoire, release 1.5 (an indexed file and screen display program) for the set of routines, and JPI Modula-2 as the screen compiler. Development of the two programs took about 400 hours of a reference librarian's time, in addition to 30 hours of the professional pro-grammer's time.
Both programs are installed on networks at the two campus microcomputer facilities and can be accessed by the students 93 hours a week. On logging into one of the programs, students are asked their name, their biology lab session, and their lab instructor's name. The program records this information and later reports the names of the students who have gone through each program, sorted by lab instructor. The instructor can then give them credit for completing the assignment.

\section{The Online Catalog Program}

The CAI program for the online catalog is a brief introduction to the system and can be completed in about 30 minutes. It teaches the students how to find books and journals using significant title words and explains three ways of displaying the data. Banners displayed at the bottom of each screen direct students through the program.

Throughout the program there are simulations of real searches. To demonstrate how the system works, students enter commands on copies of screens taken from the online cata$\log$, and the program answers with authentic catalog responses. These simulations help students recognize many of the system's features and feel confident of their searching ability when they first use the online catalog in the library.

\section{The Bio Indexes Program}

The other CAI program was expanded to a more general introduction to indexes and their use in finding information in the life sciences. It now covers the importance of information in scientific research, journal citations and their interpretation, and the use of both Biological and Agricultural Index and Biological $A b$ stracts.

The program, which takes 45 minutes to an hour to complete, consists of a series of screens that explain and illustrate these concepts, with review questions appearing every third or fourth screen. At intervals the program refers to a sample packet of 21 pages from Biological and Agricultural Index and Biological Abstracts (reproduced with permission). Students are asked to use this packet as a sample index to find several scientific articles. Citations for these articles must then be entered correctly on the terminal. Students become familiar with the indexes without having to use the real volumes. As in the other CAI program, banners at the bottom of each screen direct students through the program. 


\section{ALL THE OPTIONS FOR DATA DELIVERY}

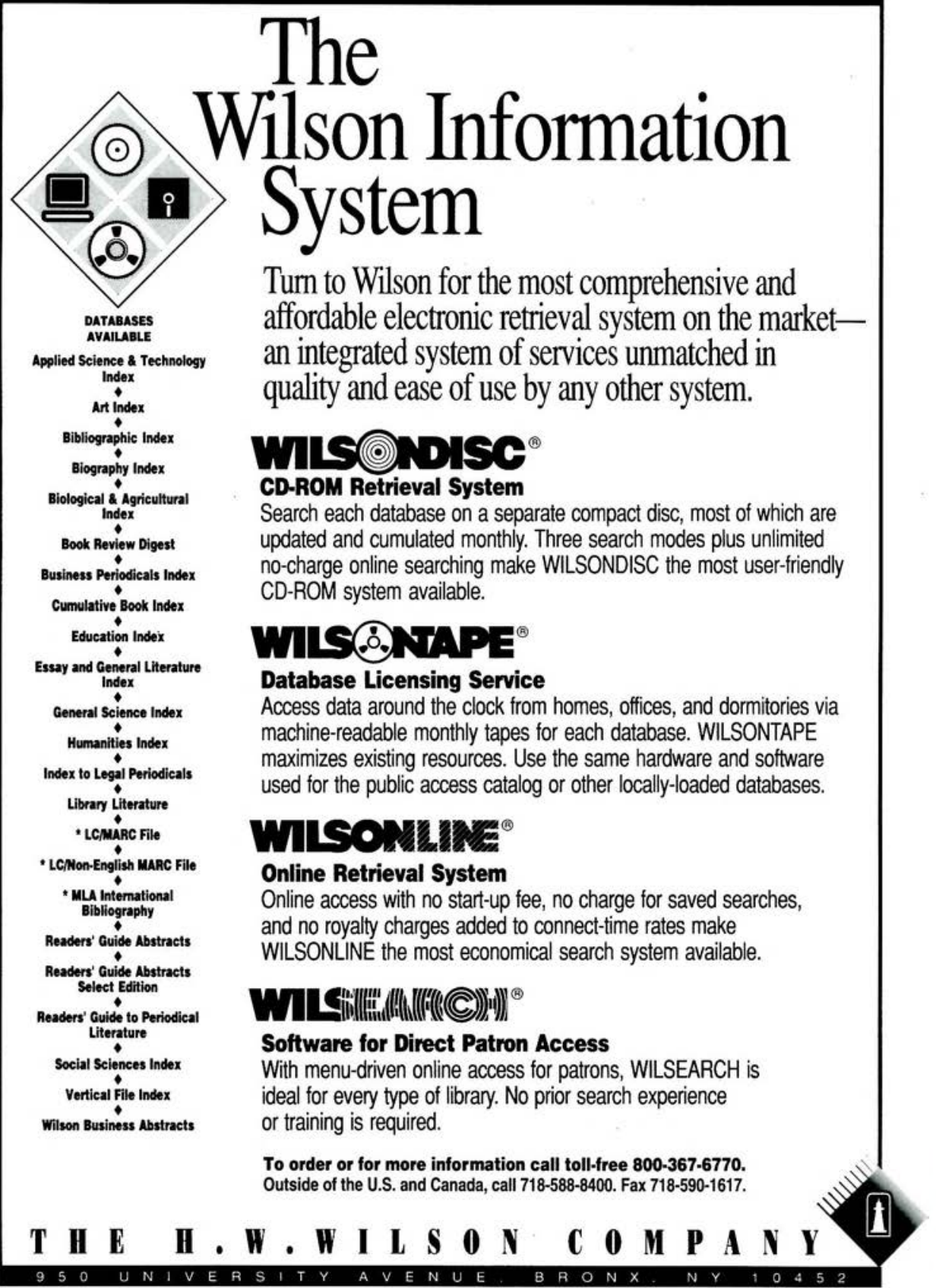




\section{New Library Skills Program}

With the two CAI programs in place, we were able to make significant revisions in the library orientation. Biology 5A students are now asked to go through the programs on either of the campus PC-network facilities during the first two weeks of the quarter. Those who are unfamiliar with computers are urged to seek individual help from our reference librarians. Although the number who ask for this help is relatively small, we have been somewhat surprised that in a time when students are reputed to be "computer literate," there are still those who feel unsure of their abilities in this area. After completing this assignment, the class is divided into groups of about 20 students who come to the BioAgricultural Library for a brief exercise in ways of finding material on the shelves.

In the exercise each student is given a different citation to a journal article which they are to assume they have found in Biological Abstracts. Following a brief tour of the library, the students work through the exercise, finding the call number for their cited journal from the online catalog, and locating the journal using library floor maps. After going to the shelves and finding the correct journal volume, they turn to the end of the cited article and record the citation for the first reference on their exercise sheet. The sheet is then turned in as evidence that they have completed the assignment.

Instead of the formal follow-up library exercise included in past orientations, we now ask the instructors to require library research for reports assigned in the introductory course and also in later, more advanced courses. The students are told of this requirement at the start of the library orientation, giving them additional motivation to participate in the program. In all phases of the orientation we have found that a close working relationship with the course professors and laboratory instructors has been essential to the program's success.

\section{Evaluation}

We have now oriented 1,680 students using the new instructional program. In anonymous evaluations $62 \%$ of these students gave ratings of very good or excellent to the skills and knowledge they received from the CAI programs, and $72 \%$ gave the same ratings to the clearness of the material presented in the programs. The final library exercise received similar ratings from the students, although they suggested several minor adjustments that will make the program run more smoothly in the future. Overall, the students evaluated the program very highly and indicated by their comments that they felt it was a worthwhile investment of their time.

However, the evaluations showed some dissatisfaction with the use of CAI in teaching library skills. In fact, 29 students (2\%) said that they did not like to use a computer for this type of assignment, and there were additional written comments indicating resistance to the depersonalization inherent in this type of instruction. On the other hand, the overwhelming majority were positive about the experience and some even asked for more CAI programs in the future.

The Biology Department has also been enthusiastic about the new program, stressing the importance of the orientation to the students. Such support is vital to its success because completion of the program counts for only 12 points out of the total 320 points in a student's final course grade. As might be expected, a few students (about 5\%) choose not to participate in the orientation, but all of the others have willingly participated, undoubtedly stimulated by the professors and laboratory instructors.

The new program requires about 60 hours of library staff time per quarter, most of it spent guiding the students through the library exercise. This is a significant decrease over the time spent on previous orientations. The staff notes that students who have been through the orientation seem to be more confident in their use of the library. The overall assessment of our librarians is that the program is effective in helping these students learn ways of locating scientific information in the library.

\section{Summary}

We believe the program is a success from the standpoint of the students, the Biology Department, and the library. The use of ComputerAssisted Instruction has simplified our task of orienting large groups of students while still giving them basic training in the use of a library. Most of the students like this instructional format, especially since they have some control over the various phases of the orientation and can schedule them around other assignments. The evidence indicates that they are also retaining many of the library skills being taught - a benefit both to them and to the Biology Department's Instructional Program. 